\title{
PMSMs Torque Estimation Using Pulsating HF Current Injection
}

\author{
Maria Martinez, David Reigosa, Daniel Fernández, J. M. Guerrero and Fernando Briz \\ "University of Oviedo. Dept. of Elect., Computer \& System Engineering, Gijón, 33204, Spain. \\ martinezgmaria@uniovi.es, diazdavid@uniovi.es, fernandezalodaniel@uniovi.es, guerrero@uniovi.es, \\ fernando@isa.uniovi.es
}

\begin{abstract}
Torque estimation in permanent magnet synchronous machines (PMSMs) is highly desirable in many applications. Torque produced by a PMSM depends on the permanent magnets' (PM) flux and dq-axis inductances. Consequently, precise knowledge of these parameters is required for proper torque estimation. This paper proposes the use of a high frequency (HF) signal for PM flux and dq-axis inductances estimation. The HF signals will be injected in the stator via inverter superposed on top of the fundamental excitation. Appealing properties of this method include operation in real time, without interference with the normal operation of the machine and independent of machine working condition. ${ }^{1}$
\end{abstract}

Index Terms - High frequency signal injection, permanent magnet synchronous machines, temperature estimation, magnetization state estimation.

\section{Introduction}

Design and control of permanent magnet synchronous machines (PMSMs) has been the focus of significant research efforts during the last decades due to their high dynamic performance, torque density and efficiency. Many applications require precise control of the torque produced by the machine, torque measurement/estimation being therefore needed.

If torque is to be measured, torque transducers based on strain gauges are likely the preferred option [1]-[5]. However, these type of sensors can introduce resonances into the system, are highly sensitive to electromagnetic interference and their cost could account for a significant portion of the drive cost [6]. Less popular alternatives for torque measurement are systems based on torsional displacement [7]. Torsional displacement methods are immune to electromagnetic noise but they use optical probes, which are expensive and require accurate calibration [7]. Regardless of the method being used, precise torque measurement is expensive and requires room and extra cables. Due to this, torque estimation is preferred.

${ }^{1}$ This work was supported in part by the Spanish Ministry of Economy and Competitiveness under grant MINECO-17-ENE2016-80047-R. M. Martinez, D. Reigosa, D. Fernández, J. M. Guerrero and F. Briz are with the Department of Electrical, Computer \& System Engineering, University of Oviedo, Campus de Gijón, 33204, Gijón, Spain.

978-1-5386-4455-3/18/\$31.00 C2018 IEEE
Torque estimation methods can be roughly classified into: torque equation methods [8]-[9], indirect estimation methods [10]-[17] or neural networks [18]. Torque equation methods include methods based on general torque equation [8], flux estimation [8] or look-up-tables [9]. Indirect estimation methods include methods based on the electric power and rotor speed [10], observer based methods [11]-[16] (e.g. sliding mode observers [11], model reference adaptive systems [12]-[13], model reference observers and reduced order observers [14], recursive least square parameters estimation [15] or affine projection algorithms parameters estimation [16] being the most extended) or methods requiring additional sensors, e.g. giant magnetoresistance effect (GMR) based methods [17]. All these methods [8]-[18] require previous knowledge of certain machine parameters and/or its operating condition (e.g. temperature, resistances or inductances).

In this paper the fundamental torque equation of a PMSM will be used [19]-[20]. Torque provided by this equation depends on the permanent magnets (PM) remanent flux and on the $d q$-axis inductances [19]-[20]. These parameters must therefore be known with sufficient accuracy for reliable torque estimation. PM remanent flux and $d q$-axis inductances change during the normal operation of the machine due to fundamental current injection [21]-[24] and PM temperature [20], [25]-[32]. An increase of the PM temperature reduces the PM remanent flux (i.e. magnetization state) reducing therefore the machine torque for a given current. In addition PM remanent flux variation changes the $d$-axis saturation level (assumed that the PMs are aligned with the $d$-axis), making the $d$-axis inductance to change [20], [28]-[29]. Injection of fundamental $d q$-axis current injection changes the $d q$-axis saturation level, resulting therefore in $d q$-axis inductances variation [20], [28].

This paper proposes a method for the estimation of machine parameters involved in the torque equation, i.e. PM flux and $d q$-axis inductances. Two HF signals injected in the stator terminals of the machine via inverter will be used for this purpose. The HF signals are superposed on top of the fundamental excitation, meaning that the method will not interfere with the normal operation of the machine. The paper is organized as follows: fundamental model of a PMSM is presented in section II, torque estimation using a HF signal is presented in section III, implementation of the method is 
presented in section IV, preliminary simulation results are presented in section $\mathrm{V}$ and conclusions are provided in section VI.

\section{Fundamental model of a PMSM}

The fundamental model of a PMSM in a reference frame synchronous with the rotor is given by (1) where $R_{d}, R_{q}, L_{d}$ and $L_{q}$ are the $d$ and q-axes resistances and inductances respectively and $\lambda_{p m}$ is the PM flux. The output torque can be expressed by (2), where $P$ is the number of poles. The first term on the left-hand side of (2), $T_{s y n}$, is the electromagnetic/synchronous torque, while the second term on the right-hand side of (2), $T_{\text {rel }}$, is the reluctance torque. It can be concluded from (2) that $T_{s y n}$ estimation requires $\lambda_{p m}$ estimation, while $T_{r e l}$ requires differential inductance, i.e. $\left(L_{d^{-}}\right.$ $L_{q}$ ), estimation. It will be shown in the next section that $\lambda_{p m}$, $L_{d}$ and $L_{q}$ can be estimated by injecting two HF signals into the stator terminals of a PMSM.

$$
\begin{aligned}
{\left[\begin{array}{c}
v_{s d}^{r} \\
v_{s q}^{r}
\end{array}\right]=} & {\left[\begin{array}{cc}
R_{d} & 0 \\
0 & R_{q}
\end{array}\right]\left[\begin{array}{c}
i_{s d}^{r} \\
i_{s q}^{r}
\end{array}\right]+} \\
& p\left[\begin{array}{cc}
L_{d} & 0 \\
0 & L_{q}
\end{array}\right]\left[\begin{array}{c}
i_{s d}^{r} \\
i_{s q}^{r}
\end{array}\right]+ \\
& {\left[\begin{array}{cc}
0 & -\omega_{r} L_{q} \\
\omega_{r} L_{d} & 0
\end{array}\right]\left[\begin{array}{c}
i_{s d}^{r} \\
i_{s q}^{r}
\end{array}\right]+\left[\begin{array}{c}
0 \\
\lambda_{p m} \omega_{r}
\end{array}\right] } \\
T_{\text {out }}= & \frac{3}{2} \frac{P}{2}\left[\lambda_{p m} i_{s q}^{r}+\left(L_{d}-L_{q}\right) i_{s d}^{r} i_{s q}^{r}\right]=T_{s y n}+T_{r e l}
\end{aligned}
$$

\section{Torque estimation in PMSMs using a HF signal}

This section analyzes the physical principles of torque estimation in PMSMs using HF signal injection.

HF model of a PMSM

If the stator of a PMSM is fed with a HF voltage/current, the magnet flux dependent term in (1) can be safely neglected, as it does not contain any HF component, the resulting HF model being (3).

$$
\begin{aligned}
{\left[\begin{array}{c}
v_{s d H F}^{r} \\
v_{s q H F}^{r}
\end{array}\right] } & {\left[\begin{array}{cc}
R_{d H F} & 0 \\
0 & R_{q H F}
\end{array}\right]\left[\begin{array}{l}
i_{s d H F}^{r} \\
i_{s q H F}^{r}
\end{array}\right]+} \\
& p\left[\begin{array}{cc}
L_{d H F} & 0 \\
0 & L_{q H F}
\end{array}\right]\left[\begin{array}{l}
i_{s d H F}^{r} \\
i_{s q H F}^{r}
\end{array}\right]+ \\
& {\left[\begin{array}{cc}
0 & -\omega_{r} L_{q H F} \\
\omega_{r} L_{d H F} & 0
\end{array}\right]\left[\begin{array}{l}
i_{s d H F}^{r} \\
i_{s q H F}^{r}
\end{array}\right] }
\end{aligned}
$$

If the frequency of the injected HF signal is sufficiently higher than the rotor frequency, the rotor speed dependent terms can also be safely neglected, the simplified HF model shown in (4) being obtained. An indicative threshold for this assumption can be $\omega_{h f}>\omega_{r}+2 \cdot \pi \cdot 500$ [29].

$$
\begin{aligned}
{\left[\begin{array}{c}
v_{s d H F}^{r} \\
v_{s q H F}^{r}
\end{array}\right] } & =\left[\begin{array}{cc}
R_{d H F} & 0 \\
0 & R_{q H F}
\end{array}\right]\left[\begin{array}{c}
i_{s d H F}^{r} \\
i_{s q H F}^{r}
\end{array}\right]+ \\
& p\left[\begin{array}{cc}
L_{d H F} & 0 \\
0 & L_{q H F}
\end{array}\right]\left[\begin{array}{c}
i_{s d H F}^{r} \\
i_{s q H F}^{r}
\end{array}\right]
\end{aligned}
$$

\section{Electromagnetic torque estimation}

As shown in (2), electromagnetic torque $\left(T_{s y n}\right)$ estimation requires knowledge of PM flux, $\lambda_{p m}$. $D$-axis inductance of a PMSM, $L_{d}(1)$, has been demonstrated to be function of the PM flux [22], [29] ( $d$-axis is aligned with PMs). $\lambda_{p m}$ variation with $d$-axis inductance can be expressed by (5), where $\lambda_{p m 0}$ and $L_{d 0}$ are the PM flux and $d$-axis inductance at the room temperature $\left(T_{r 0}\right)$ and when no dq-axis fundamental current is injected respectively, $L_{d(I d . I q, T r)}$ is the $d$-axis inductance when the magnet temperature is $T_{r}$ and when $d q$-axis fundamental current is injected, and $K_{B E M F}$ is the coefficient linking the $d$ axis HF inductance with the PM flux. $D$-axis inductance variation with fundamental current and magnet temperature $\left(T_{r}\right)$ can be expressed as (6), where $\alpha_{I d}, \alpha_{I q}, \alpha_{T r}$ are the coefficients linking the $d$-axis inductance with the $d$-axis fundamental current $\left(I_{s d}^{r}\right), q$-axis fundamental current $\left(I_{s q}^{r}\right)$ and magnet temperature $\left(T_{r}\right)$. $D$-axis inductance depends on $I_{s d}^{r}$ due to saturation while dependence on $I_{s q}^{r}$ is due to crosscoupling between $d$ and $q$-axes. On the other hand, $d$-axis inductance depends on PM remanent flux, which is affected by the magnet temperature [20], [28], [29].

$$
\begin{aligned}
& \lambda_{p m}=\left(\lambda_{p m 0}+k_{B E M F} \frac{L_{d\left(I d, I q, T_{r}\right)}-L_{d 0}}{L_{d 0}}\right) \\
& L_{d\left(I d, I q, T_{r}\right)}=L_{d H F 0}\left(1+\alpha_{I d} I_{s d}^{r}+\alpha_{I q} I_{s d}^{r}+\alpha_{T_{r}}\left(T_{r}-T_{r 0}\right)\right)
\end{aligned}
$$

$D$-axis inductance can be estimated by injecting a pulsating $d$-axis HF current (7) into the stator terminals of the machine. A resonant controlled can be used to inject the HF current [29]. The HF voltages commanded by the resonant controller are (8). By taking only the $d$-axis component of the resulting HF voltage complex vector, $v_{d q s H F 1}^{r *}$ in (8), the voltage complex vector $v_{d q s H F 1}^{r^{\prime}},(9)$, is defined. Both (7) and (9) can be separated into positive sequence $\left(i_{d q s H F 1 p c}^{r^{*}}\right.$ and $\left.v_{d q s H F 1 p c}^{r^{\prime}}\right)$ and negative sequence $\left(i_{d q s H F 1 n c}^{r^{*}}\right.$ and $\left.v_{d q s H F 1 n c}^{r^{\prime}}\right)$ components, (10) and (11), each with a magnitude equal to half of that of the original signal. The $d$-axis HF impedance, (12), can be obtained either from the positive or negative sequence components. The $d$-axis HF inductance is finally obtained as the imaginary part of $d$-axis HF impedance, (13). $T_{s y n}$ estimation using pulsating $\mathrm{HF}$ current injection is schematically shown in Fig. 1.

$$
\begin{aligned}
& i_{d q S H F 1}^{r^{*}}=\left[\begin{array}{c}
\bar{I}_{d H F 1}^{r^{*}} \\
\bar{I}_{q H F 1}^{r^{*}}
\end{array}\right]=\left[\begin{array}{c}
I_{H F}^{*} \cos \left(\omega_{H F} t\right) \\
0
\end{array}\right] \\
& v_{d q s H F 1}^{r^{*}}=\left[\begin{array}{c}
\bar{V}_{d s H F 1}^{r^{*}} \\
\bar{V}_{q s H F 1}^{r *}
\end{array}\right]=\left[\begin{array}{c}
\left(R_{d H F}+j \omega_{H F} L_{d H F}\right) \bar{I}_{d H F}^{r} \\
\omega_{r} L_{d H F} \bar{I}_{d H F}^{r}
\end{array}\right]
\end{aligned}
$$




$$
\begin{aligned}
& v_{d q s H F 1}^{r^{\prime}}=\left[\begin{array}{c}
\bar{V}_{d s H F 1}^{r^{*}} \\
0
\end{array}\right]=\left[\begin{array}{c}
\left(R_{d H F}+j \omega_{H F} L_{d H F}\right) \bar{I}_{d H F}^{r^{*}} \\
0
\end{array}\right] \\
& =\left[\begin{array}{c}
V_{d q s H F}^{r^{\prime}} \cos \left(\omega_{H F} t+\varphi_{Z d}\right) \\
0
\end{array}\right] \\
& i_{d q S H F 1}^{r^{*}}=\frac{I_{H F}^{*}}{2} e^{j \omega_{H F} t}+\frac{I_{H F}^{*}}{2} e^{-j \omega_{H F} t} \\
& =i_{d q s H F 1 p c}^{r^{*}}+i_{d q s H F 1 n c}^{r^{*}} \\
& v_{d q s H F 1}^{r^{\prime}}=\frac{\left|v_{d q s H F 1}^{r^{\prime}}\right|}{2} e^{j\left(\omega_{H F} t-\varphi_{Z d}\right)}+\frac{\left|v_{d q s H F 1}^{r^{\prime}}\right|}{2} e^{j\left(-\omega_{H F} t+\varphi_{Z d}\right)} \\
& =v_{d q s H F 1 p c}^{r^{\prime}}+v_{d q s H F 1 n c}^{r^{\prime}} \\
& Z_{d H F}=R_{d H F}+j \omega_{H F} L_{d H F}=\frac{v_{d q s H F p c}^{r^{\prime}}}{i_{d q s H F p c}^{r^{*}}}=\frac{v_{d q s H F n c}^{r^{\prime \prime}}}{i_{d q s H F n c}^{r^{*}}} \\
& L_{d H F}=\mathfrak{I}\left[Z_{d H F}\right]
\end{aligned}
$$

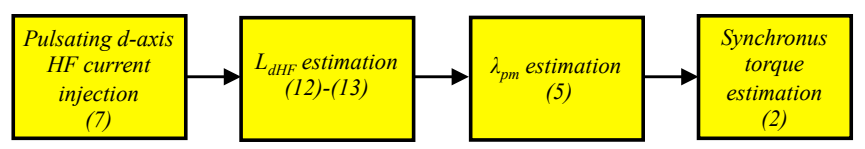

Fig. 1.-. Schematic representation of the process followed to estimate the synchronous torque using pulsating HF current injection

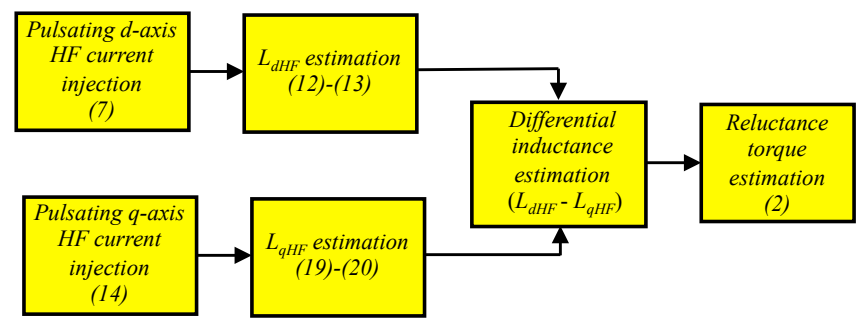

Fig. 2.-. Schematic representation of the process followed to estimate the reluctance torque using pulsating $\mathrm{HF}$ current injection

\section{Reluctance torque estimation}

As shown in (2), reluctance torque $\left(T_{r e l}\right)$ estimation requires knowledge of the differential inductance $\left(L_{d}-L_{q}\right)$. Daxis inductance $\left(L_{d}\right)$ can be estimated by injecting a pulsating $d$-axis HF current as shown in (7)-(13). $Q$-axis inductance $\left(L_{q}\right)$ can be estimated by injecting a pulsating $q$-axis HF current (14)-(20). $T_{\text {rel }}$ estimation using pulsating HF current injection is schematically shown in Fig. 2.

$$
\begin{aligned}
& i_{d q s H F 2}^{r^{*}}=\left[\begin{array}{c}
\bar{I}_{d H F}^{r^{*}} \\
\bar{I}_{q H F}^{r *}
\end{array}\right]=\left[\begin{array}{c}
0 \\
I_{H F}^{*} \cos \left(\omega_{H F} t\right)
\end{array}\right] \\
& v_{d q s H F 2}^{r^{* *}}=\left[\begin{array}{c}
\bar{V}_{d s H F 2}^{r^{*}} \\
\bar{V}_{q s H F 2}^{r^{*}}
\end{array}\right]=\left[\begin{array}{c}
\omega_{r} L_{q H F} \bar{I}_{q H F}^{r} \\
\left(R_{q H F}+j \omega_{H F} L_{q H F}\right) \bar{I}_{q H F}^{r}
\end{array}\right]
\end{aligned}
$$

$$
\begin{aligned}
& v_{d q s H F 2}^{r^{\prime}}=\left[\begin{array}{c}
0 \\
\bar{V}_{q s H F 2}^{r^{*}}
\end{array}\right]=\left[\begin{array}{c}
0 \\
\left(R_{q H F}+j \omega_{H F} L_{q H F}\right) \bar{I}_{q H F}^{r}
\end{array}\right] \\
& =\left[\begin{array}{c}
0 \\
V_{d q s H F}^{r^{\prime}} \cos \left(\omega_{H F} t+\varphi_{Z d}\right)
\end{array}\right] \\
& i_{d q s H F 2}^{r^{*}}=\frac{I_{H F}^{*}}{2} e^{j \omega_{H F} t}+\frac{I_{H F}^{*}}{2} e^{-j \omega_{H F} t} \\
& =i_{d q s H F 2 p c}^{r^{*}}+i_{d q s H F 2 n c}^{r^{*}} \\
& v_{d q s H F 2}^{r^{\prime}}=\frac{\left|v_{d q s H F 2}^{r^{\prime}}\right|}{2} e^{j\left(\omega_{H F} t-\varphi_{Z d}\right)}+\frac{\left|v_{d q s H F 2}^{r^{\prime}}\right|}{2} e^{j\left(-\omega_{H F} t+\varphi_{Z d}\right)} \\
& =v_{d q s H F 2 p c}^{r^{\prime}}+v_{d q s H F 2 n c}^{r^{\prime}} \\
& Z_{q H F}=R_{q H F}+j \omega_{H F} L_{q H F}=\frac{v_{d q s H F 2 p c}^{r^{\prime}}}{i_{d q s H F 2 p c}^{r^{*}}}=\frac{v_{d q s H F 2 n c}^{r^{\prime}}}{i_{d q s H F 2 n c}^{r^{*}}} \\
& L_{q H F}=\mathfrak{I}\left[Z_{q H F}\right]
\end{aligned}
$$

\section{Implementation}

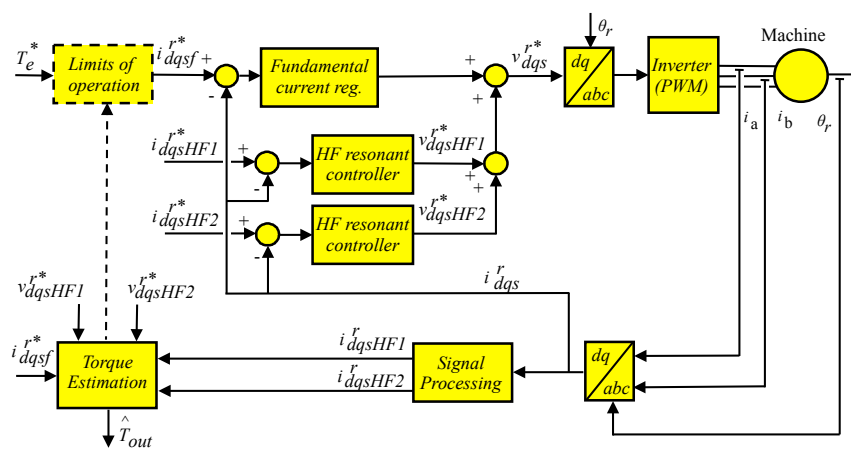

Fig. 3.- Injection of HF pulsating currents. Dashed lines indicate optional functionalities.

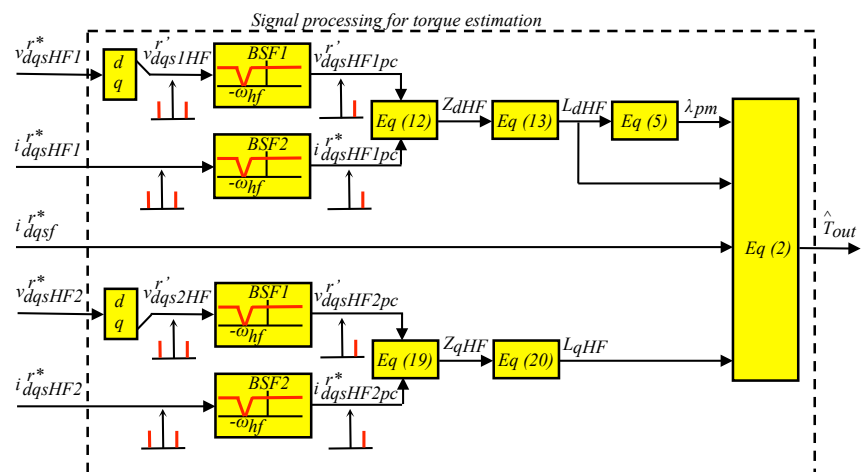

Fig. 4.- Schematic representation of the signal processing for torque estimation using pulsating HF current injection.

Fig. 3 shows the general block diagram used for the implementation of the method, including inverter control and injection of pulsating HF signals; torque estimation requires the injection of two HF pulsating signals, to estimate $L_{d H F}$ and $\lambda_{p m}$, and to estimate $L_{q H F}$ respectively. Fig. 4 shows the signal processing required for torque estimation. Inputs to the torque estimation block are the output voltage of the HF resonant 


\begin{tabular}{|c|c|c|c|c|}
\hline \multicolumn{5}{|c|}{ TABLE 1. MACHINE PARAMETERS } \\
\hline $\mathrm{P}_{\text {Rated }}[\mathrm{kW}]$ & $\mathrm{V}_{\text {Rated }}[\mathrm{V}]$ & $\mathrm{I}_{\text {Rated }}[\mathrm{A}]$ & $\omega_{r}[\mathrm{rpm}]$ & Poles \\
\hline 7.5 & 350 & 14 & 1000 & 6 \\
\hline
\end{tabular}

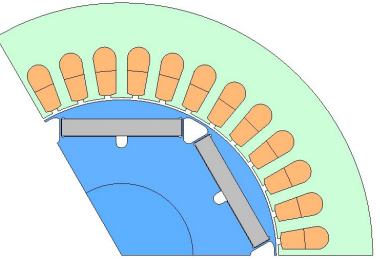

Fig. 5.- Schematic representation of the test machine.

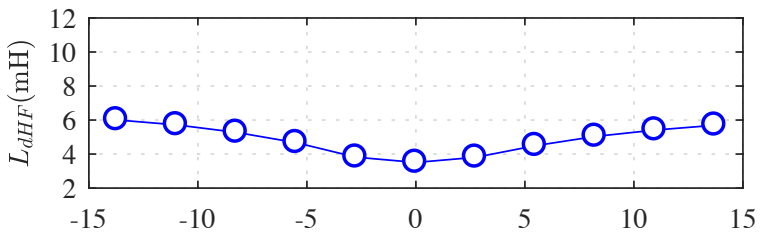

a)

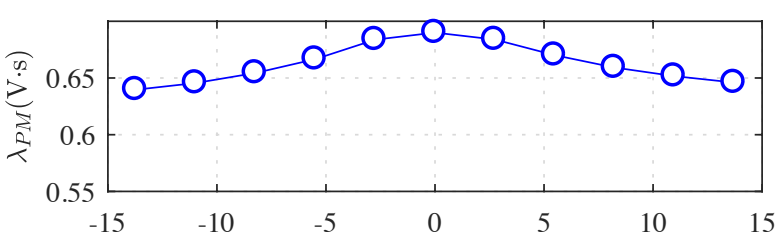

b)

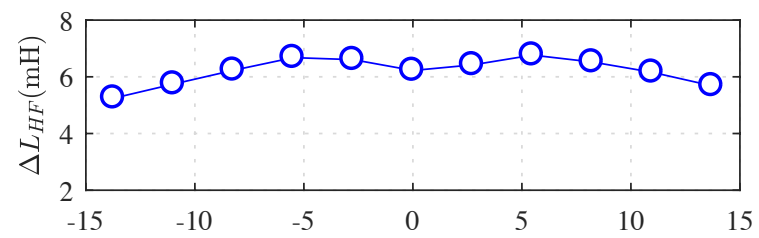

c)

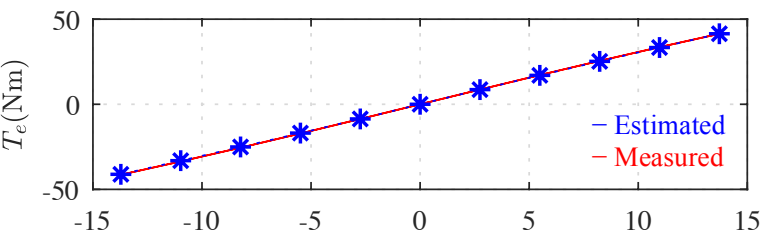

d)

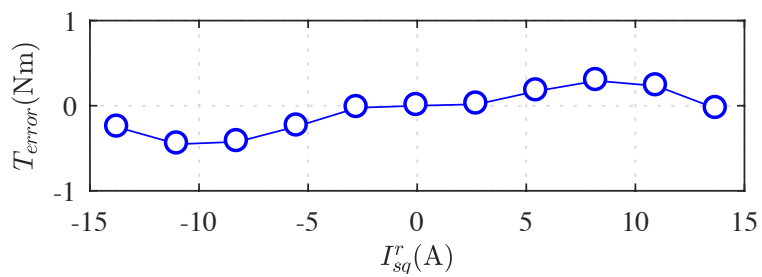

e)

Fig. 6.- FEM results. (a) Estimated $d$-axis $\mathrm{HF}$ inductance, $\mathrm{L}_{\mathrm{dHF}}$. (b) Estimated $q$-axis $\mathrm{HF}$ inductance, $\mathrm{L}_{\mathrm{qHF}}$. (c) Estimated PM flux, $\lambda_{p m}$. (d) Estimated and measured torque. (e) Estimated torque error. $-1<I_{s q}^{r}<1 \mathrm{pu}$, $I_{s d}^{r}=0 \mathrm{pu}, T_{r}=20^{\circ} \mathrm{C}, \omega_{\mathrm{HF} 1}=2 \cdot \pi \cdot 500 \mathrm{rad} / \mathrm{s}$ and $I_{\mathrm{HF} 1}=0.05 \mathrm{pu}, \omega_{\mathrm{HF} 2}=2 \cdot \pi \cdot$ $1000 \mathrm{rad} / \mathrm{s}$ and $I_{\mathrm{HF} 2}=0.05 \mathrm{pu}, \omega_{\mathrm{HF} 2}=2 \cdot \pi \cdot 50 \mathrm{rad} / \mathrm{s}$.

current controllers $v_{d q s H F l_{*}}^{r^{*}}$ (9) and $v_{d q s H F 2}^{r^{*}}$ (16), the commanded HF currents $i_{d q s H F F^{\prime *}}^{r^{*}}(7)$ and $i_{d q s H F 2}^{r^{r}}(14)$ and the injected fundamental current $i_{d q s}^{r^{*}}$, see Fig. 3. Two band stop filters, $B S F 1$ and $B S F 2$, are used to remove the negative sequence components of the HF currents and voltages. The $d$ and $q$-axis HF impendences are estimated using (12) and (19), the $d$ and $q$-axis HF inductances are estimated using (13) and (20), the PM flux is estimated using (5) and the torque is finally estimated using (2).

\section{FEM results}

Preliminary simulation results showing the performance of the proposed method are presented in this section. Fig. 5 shows the schematic representation of the machine that will be used for verification of the method, the parameters being shown in Table I.

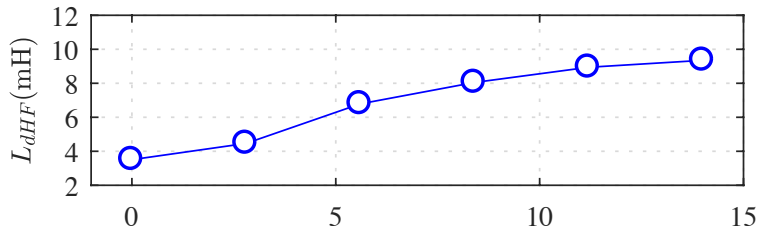

a)

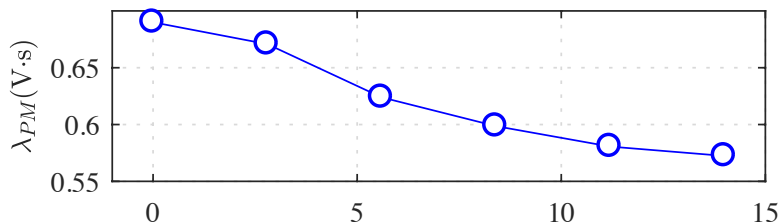

b)

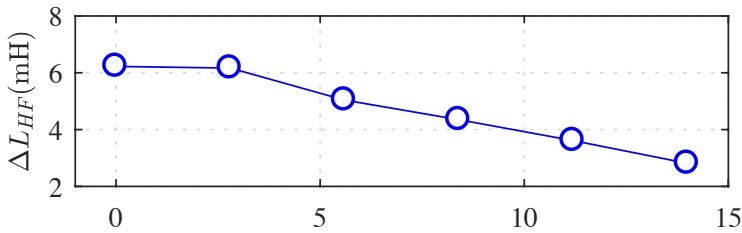

c)

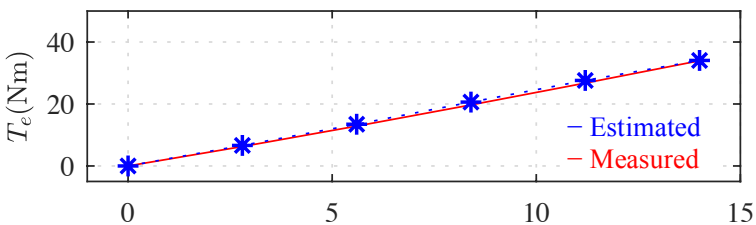

d)

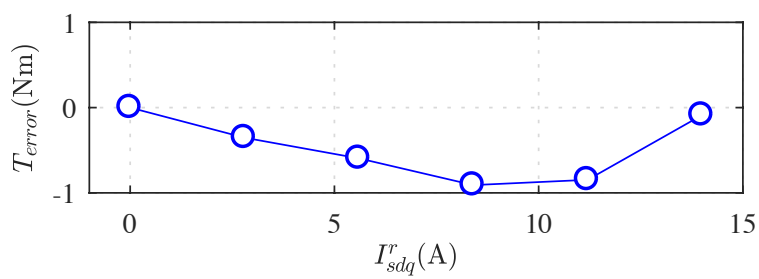

Fig. 7.- FEM results. (a) Estimated $d$-axis HF inductance, $\mathrm{L}_{\mathrm{dHF}}$. (b) Estimated $q$-axis HF inductance, $\mathrm{L}_{\mathrm{qHF}}$. (c) Estimated PM flux, $\lambda_{p m}$. (d) Estimated and measured torque. (e) Estimated torque error. $0<I_{s d q}^{r}<1 \mathrm{pu}$ ( $\left.I_{s q}^{r}=-I_{s d}^{r}\right), T_{r}=20^{\circ} \mathrm{C}, \omega_{\mathrm{HF} 1}=2 \cdot \pi \cdot 500 \mathrm{rad} / \mathrm{s}$ and $I_{\mathrm{HF} 1}=0.05 \mathrm{pu}, \omega_{\mathrm{HF} 2}=2 \cdot \pi$ $\cdot 1000 \mathrm{rad} / \mathrm{s}$ and $I_{\mathrm{HF} 2}=0.05 \mathrm{pu}, \omega_{\mathrm{HF} 2}=2 \cdot \pi \cdot 50 \mathrm{rad} / \mathrm{s}$.

Fig. 6 shows machine response obtained by FEM when the magnitude of the $q$-axis component of the fundamental current, $I_{s q}^{r}$, changes from $-1 \mathrm{pu}$ to $1 \mathrm{pu}$. D-axis component of the fundamental current, $I_{s d}^{r}$, is $0 \mathrm{pu}$ and the PM temperature is constant. Fig. 6a shows the estimated $d$-axis HF inductance (13), $\mathrm{L}_{\mathrm{dHF}}$; a pulsating $\mathrm{HF}$ signal of $500 \mathrm{~Hz}$ and $0.05 \mathrm{pu}$ amplitude has been injected in the $d$-axis for this purpose. Fig. 6b shows the estimated PM flux, $\lambda_{p m}$; $\mathrm{L}_{\mathrm{dHF}}$ shown in Fig. 6a being used to estimate $\lambda_{p m}$ (5). $\lambda_{p m}$ is used to estimate the electromagnetic/synchronous torque (2). Fig. 6c shows the estimated differential inductance, i.e. $\mathrm{L}_{\mathrm{qHF}}-\mathrm{L}_{\mathrm{dHF}}$, which will be used to estimate the reluctance torque (2); $\mathrm{L}_{\mathrm{qHF}},(20)$, being estimated using a pulsating $q$-axis $\mathrm{HF}$ current of $1000 \mathrm{~Hz}$ and $0.05 \mathrm{pu}$ amplitude. Fig. $6 \mathrm{~d}$ shows the estimated, (2), and 
a)

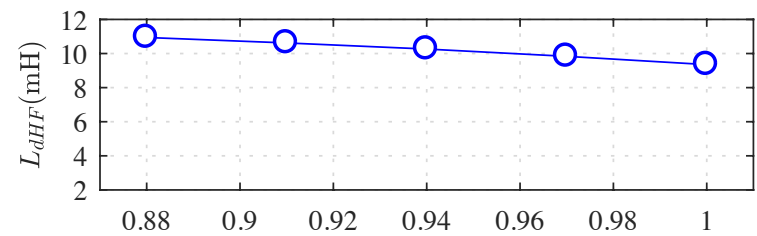

b)
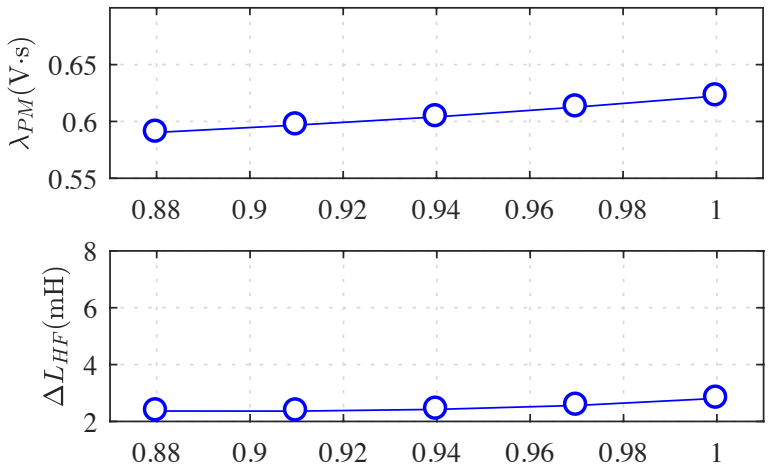

c)

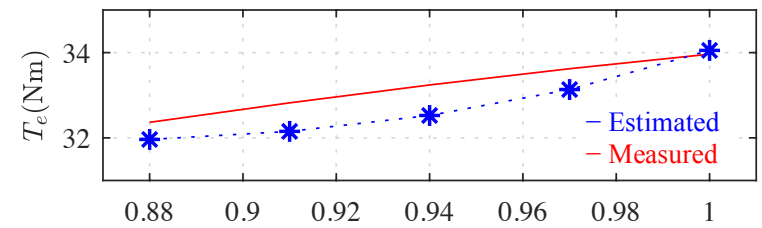

d)

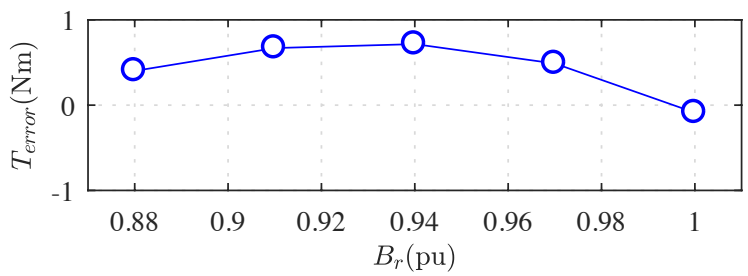

e)

Fig. 8.- FEM results. (a) Estimated $d$-axis HF inductance, $\mathrm{L}_{\mathrm{dHF}}$. (b) Estimated $q$-axis $\mathrm{HF}$ inductance, $\mathrm{L}_{\mathrm{qHF}}$. (c) Estimated PM flux, $\lambda_{p m}$. (d) Estimated and measured torque. (e) Estimated torque error. $I_{s d q}^{r}=1 \mathrm{pu}$ ( $I_{s q}^{r}=-I_{s d}^{r}$ ), $20<T_{r}<150^{\circ} \mathrm{C}$ (i.e. $0.88<B_{r}<1 \mathrm{pu}$ ), $\omega_{\mathrm{HF} 1}=2 \cdot \pi \cdot 500 \mathrm{rad} / \mathrm{s}$ and $I_{\mathrm{HF} 1}=0.05 \mathrm{pu}, \omega_{\mathrm{HF} 2}=2 \cdot \pi \cdot 1000 \mathrm{rad} / \mathrm{s}$ and $I_{\mathrm{HF} 2}=0.05 \mathrm{pu}, \omega_{\mathrm{HF} 2}=2 \cdot \pi \cdot 50$ $\mathrm{rad} / \mathrm{s}$.

measured torque of the machine while Fig. 6e shows the error in the torque estimation, which is observed to be $<0.2 \mathrm{Nm}$.

Fig. 7 shows analogous results when the fundamental current magnitude $\left|i_{s d q}^{r}\right|=I_{s d q}^{r}$, changes from $0 \mathrm{pu}$ to $1 \mathrm{pu}$, $I_{s q}^{r}=-I_{s d}^{r}\left(-I_{s d}^{r}<0\right.$, i.e. flux weakening current $)$ It is observed from Fig. 7e that the error in the estimated torque in this case is $<0.8 \mathrm{Nm}$.

Finally Fig. 8 shows analogous results to Fig. 6 but when $\left|i_{s d q}^{r}\right|=I_{s d q}^{r}=1 \mathrm{pu}\left(I_{s q}^{r}=-I_{s d}^{r}\right)$ and PM temperature changes from $20^{\circ} \mathrm{C}$ to $140^{\circ} \mathrm{C}$. An increase of the $\mathrm{PM}$ temperature will result in a reduction of $\mathrm{PM}$ remanent flux, $\mathrm{B}_{\mathrm{r}}$. The machine used for simulation is equipped with NEOMAX-42SH PMs, which for an increase from $20^{\circ} \mathrm{C}$ to $140^{\circ} \mathrm{C}$ experience a reduction of $\mathrm{B}_{\mathrm{r}}$ from 1 to $0.88 \mathrm{pu}$. It is observed from Fig. 8e that the error in the estimated torque in this case is $<0.7 \mathrm{Nm}$.

\section{Conclusions}

This paper proposes PMSMs torque estimation using the torque equation enhanced with online parameters estimation using HF signal injection. The HF signals are superposed on top of the fundamental excitation, allowing therefore real time torque estimation for any operating condition and without interfering with the normal operation of the machine. Extensive FEM results have been provided to demonstrate the viability of the proposed method.

\section{References}

[1] http://www.interfacetorque.co.uk

[2] https://www.hbm.com

[3] http://www.futek.com

[4] http://www.magtrol.com/torque

[5] http://www.te.com

[6] G. Heins, M. Thiele and T. Brown, "Accurate Torque Ripple Measurement for PMSM." IEEE Transactions on Instrumentation and Measurement, 60(12): 3868-3874, Dec. 2011.

[7] P. Sue, D. Wilson, L. Farr and A. Kretschmar, "High precision torque measurement on a rotating load coupling for power generation operations," IEEE International Instrumentation and Measurement Technology Conference Proceedings, pp. 518-523, May 2012.

[8] K. C. Yeo, G. Heins and F. De Boer, "Comparison of torque estimators for PMSM," AUPEC, pp. 1-6, 2008.

[9] B. Cheng and T. R. Tesch, "Torque Feedforward Control Technique for Permanent-Magnet Synchronous Motors", IEEE Trans. on Ind.Electr., 57(3): 969-974, March 2010.

[10] F. Jukic, D. Sumina and I. Erceg, "Comparison of Torque Estimation Methods for Interior Permanent Magnet Wind Power Generator", IEEE EDPE, pp. 291-296, Oct. 2017.

[11] Weizhe Qian, S.K. Panda, and Jian-Xin Xu, "Improved PMSM pulsating torque minimization with iterative learning and sliding mode observer", IECON, pp. 1931-1936, 2000

[12] B. H. Lam, S. K. Panda, J. x. Xu and K.W. Lim 'Torque ripple minimization in PM synchronous motor using iterative learning control', IEEE PED, pp. 141-149, 1999.

[13] S. -K. Chung, H. -S. Kim, C. -G. Kim and M. -J. Youn, 'A new instantaneous torque control of PM synchronous motor for highperformance direct drive applications', IEEE Trans. Power Elect., 13(3): 388-400, May 1998

[14] Xu Dong and Wang Tianmiao and Wei Hongxing, "Comparison between model reference observer and reduced order observer of PMSM torque", IEEE-ICIEA, pp. 663-667, 2011.

[15] Q. Liu and K. Hameyer "High-Performance Adaptive Torque Control for an IPMSM With Real-Time MTPA Operation ", IEEE Trans. on Energy Conv., 32(2): 571-581, June 2017.

[16] Y.-R. Mohamed and T. K. Lee, "Adaptive self-tuning MTPA vector controller for IPMSM drive system," IEEE Trans. Energy Conv., 21(3): 636-644, Sep. 2006

[17] W. F. Traoré and R. McCann, "Torque measurements in synchronous generators using giant magnetoresistive sensor arrays via the Maxwell stress tensor," IEEE Power \& Energy Society General Meeting, pp. 1-5, Jul 2013.

[18] Z. Lin, D. S. Reay, B. W. Williams, and X. He, "Online modeling for switched reluctance motors using B-spline neural networks," IEEE Trans. Ind. Electron., 54(6): 3317-3322, Dec. 2007.

[19] D. W. Novotny and T. A. Lipo, "Vector Control and Dynamics of AC Drives," Oxford Science Publications, 1996.

[20] J. F. Gieras and M. Wing, "Permanent magnet motor technology: design and application". Second edition 2002

[21] N. Limsuwan, T. Kato, K. Akatsu, and R. D. Lorenz, "Design and evaluation of a variable-flux flux-intensifying interior permanent-magnet machine," IEEE Trans. Ind. Appl., 50(2): 1015-1024, Mar./Apr. 2014.

[22] Fukushige, N. Limsuwan, T. Kato, K. Akatsu, and R. D. Lorenz, "Efficiency contours and loss minimization over a driving cycle of a variable flux-intensifying machine,'IEEE Trans. Ind. Appl., 51(4): 29842989, Jul./Aug. 2015

[23] B. S. Gagas, K. Sasaki, T. Fukushige, A. Athavale, T. Kato, and R. D. Lorenz, "Analysis of magnetizing trajectories for variable flux PM synchronous machines considering voltage, high-speed capability, torque ripple, and time duration," IEEE Trans. Ind. Appl., 52(5): 4029-4038, Sep./Oct. 2016 
[24] Athavale, K. Sasaki, B. S. Gagas, T. Kato, and R. D. Lorenz, "Variable Flux Permanent Magnet Synchronous Machine (VF-PMSM) Design Methodologies to Meet Electric Vehicle Traction Requirements with Reduced Losses," IEEE Trans. Ind. Appl., 53(5): 4318-4326, Sep./Oct. 2016.

[25] D. Reigosa, F. Briz, M. W. Degner, P. García and J. M. Guerrero, "Magnet temperature estimation in surface PM machines during six-Step operation”. IEEE Trans. on Ind. Appl., 48(6): 2353-2361, Nov.-Dec. 2012.

[26] D. Reigosa, D. Fernandez, T. Tanimoto, T. Kato, F. Briz, "Permanent Magnet Temperature Distribution Estimation in Permanent Magnet Synchronous Machines Using Back Electromotive Force Harmonics", IEEE Trans. on Ind. Appl., 52(4): 3093-3103 July/Aug. 2016.

[27] D. Reigosa, D. Fernandez, T. Tanimoto, T. Kato, F. Briz, "Sensitivity Analysis of High-Frequency Signal Injection-Based Temperature Estimation Methods to Machine Assembling Tolerances", IEEE Transactions on Industry Applications, 52(6): 4798-4805 Nov./Dec. 2016.

[28] D. Reigosa, D. Fernandez, T. Tanimoto, T. Kato, F. Briz, "Comparative Analysis of BEMF and Pulsating High Frequency Current Injection Methods for PM Temperature Estimation in PMSMs", IEEE Trans. on Power Elect., 32(5): 3691-3699, May 2017.

[29] D. Reigosa, D. Fernandez, H. Yoshida, T. Kato and F. Briz "PermanentMagnet Temperature Estimation in PMSMs Using Pulsating HighFrequency Current Injection," IEEE Trans. on Ind. Appl., 51(4): 31593168, July-Aug 2015.

[30] D. Reigosa, D. Fernandez, J. M. Guerrero, Z.Q. Zhu and F. Briz, "PMSM Magnetization State Estimation Based on Stator-reflected PM Resistance Using High Frequency Signal Injection”, IEEE Trans. on Ind. Appl., 51(5): 3800-3810, Sept.-Oct. 2015.

[31] D. Fernandez, D. Reigosa, Z.Q. Zhu and F. Briz, "Permanent-Magnet Magnetization State Estimation Using High-Frequency Signal Injection", IEEE Trans. on Ind. Appl., 52(4): 2930-2949, July-Aug. 2016.

[32] D. Reigosa, D. Fernandez, Yonghyun Park, A. B. Diez, S. B. Lee and F. Briz, "Detection of Demagnetization in Permanent Magnet Synchronous Machines Using Hall-Effect Sensors", IEEE-ECCE'17, pp. 4686-4693, Oct 2017.

[33] X. Xiao, C. Chen and M. Zhang, "Dynamic Permanent Magnet Flux Estimation of Permanent Magnet Synchronous Machines", IEEE Trans. on Appl. Sup., 20(3): 1085-1088, June. 2010.

[34] K. Liu and Z. Q. Zhu "Online Estimation of the Rotor Flux Linkage and Voltage-Source Inverter Nonlinearity in Permanent Magnet Synchronous Machine Drives," IEEE Trans. on Pow. Elect., 29(1): 418-427, Jan. 2014.

[35] K. Liu, Q. Zhang, J. Chen, Z. Q. Zhu, and J. Zhang, "Online multiparameter estimation of nonsalient-pole PM synchronous machines with temperature variation," IEEE Trans. Ind. Electron., 58(5): 17761788, May 2011. 